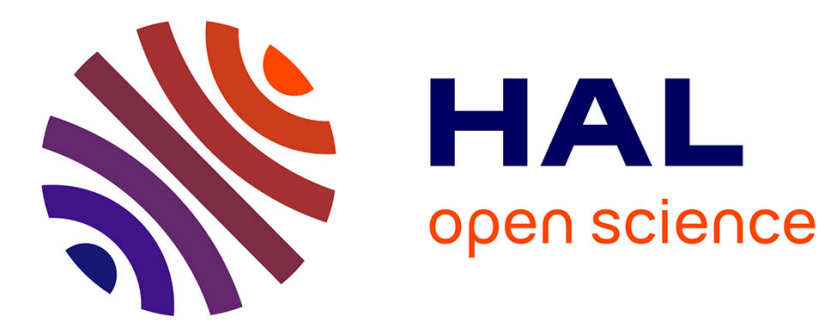

\title{
A Knowledge-Based System for Collecting and Integrating Production Information
}

\author{
Giulia Bruno, Emiliano Traini, Franco Lombardi
}

\section{To cite this version:}

Giulia Bruno, Emiliano Traini, Franco Lombardi. A Knowledge-Based System for Collecting and Integrating Production Information. 20th Working Conference on Virtual Enterprises (PRO-VE), Sep 2019, Turin, Italy. pp.163-170, 10.1007/978-3-030-28464-0_15 . hal-02478786

\section{HAL Id: hal-02478786 \\ https://hal.inria.fr/hal-02478786}

Submitted on 14 Feb 2020

HAL is a multi-disciplinary open access archive for the deposit and dissemination of scientific research documents, whether they are published or not. The documents may come from teaching and research institutions in France or abroad, or from public or private research centers.
L'archive ouverte pluridisciplinaire HAL, est destinée au dépôt et à la diffusion de documents scientifiques de niveau recherche, publiés ou non, émanant des établissements d'enseignement et de recherche français ou étrangers, des laboratoires publics ou privés. 


\title{
A Knowledge-based System for Collecting and Integrating Production Information
}

\author{
Giulia Bruno, Emiliano Traini and Franco Lombardi \\ Politecnico di Torino, Department of Management and Production Engineering, \\ Corso Duca degli Abruzzi 24, 10129 Torino, Italy \\ \{giulia.bruno,emiliano.traini,franco.lombardi\}@polito.it
}

\begin{abstract}
Design and production departments are scarcely integrated in manufacturing companies. This fact, especially for companies with a highly customized production, is very critical, since the collaboration between the two departments is essential to reduce the trial-and-errors cycles to design new products and process. It is therefore necessary to collect data from the shop floor, especially the ones related to anomalies or critical situations, and make them at disposal to be used to improve the design of the next products and processes. The aim of this paper is to develop a knowledge-based system to digitalize and collect data regarding anomalies at the shop floor, and to integrate them with data coming from the design phase, in order to reduce the time for finalizing a new product. A case study has been developed for a car prototyping company to illustrate the potentiality of the proposed solution.
\end{abstract}

Keywords: Industry 4.0, PLM, MES, knowledge management.

\section{Introduction}

Today market is characterized by a by high volatility and quick dynamics. To compete in such market, small and medium sized manufacturing companies focus on product innovation and customization [1-3]. Effective collaboration and knowledge sharing among experts and technicians is the winning strategy for such manufacturing systems. In fact, decision making mainly relies on the human learning process based on product case-histories, which enables operators to react autonomously to improve the manufacturability. In addition, companies are addressing a digital transformation, by using data to improve their production processes and achieve greater consistency.

Several commercial software applications are already available for product lifecycle management (PLM) and manufacturing execution control (MES). PLM systems make at disposal of designers shared product databases. The fact that PLM systems are accessible by different people and departments allows the collaborative development of products, enabling sharing and reuse of information. However, PLM systems are not integrated with the manufacturing execution systems (MES), which took control of the factory operations, from production order release testing of the finished product. MES systems are used to control in real time the progress of orders and to associate to each production order the information about the parameters and 
results of the operations. Through the real-time monitoring, it is therefore possible to control the progression of tasks and compare it with the production planning. In case of delays, the planning can be readjusted accordingly.

However, without a connection between PLM and MES, it is difficult for a designer to find data related to the anomalies occurred during the manufacturing process in the shop floor. This data could be of great importance at the design stage of a new product, especially for companies that realize prototypes, since, to design a new process, they usually need several trial-and-errors cycles before find the final one. For such companies, the knowledge of the trial-and-errors cycles that contribute to develop past products and processes, without the presence of a formalized and structured system, remains in the minds of the people, or, at best, transferred verbally, and then, over time, inevitably lost $[4,5]$. Similarly, it is also difficult for a production manager to find information related to the checks to perform before and after the execution of an operation on a machine, and for an operator to report in a structured way the occurrence of problems and anomalies during the production.

Based on such needs, the aim of the paper is to develop a framework able to: (i) collect data regarding anomalies at the shop floor, in addition to the other data regarding the production monitoring typical of MES systems, (ii) integrate data coming from PLM and MES to reduce the number of trial-and-errors cycles to find the final production process of a new product.

The rest of the paper is organized as follows. Section 2 summarizes the relevant literature available on the topic. Section 3 describes the proposed method and the definition of the data model to structure the knowledge-based system. Section 4 presents the application of the framework in the use case of an Italian company producing car prototypes. Finally, Section 5 draws conclusions and states future work perspectives.

\section{Related Works}

Previous works addressed the issue of structuring and formalising product-related knowledge [6-9], while several international research projects addressed the development of industrial knowledge sharing systems (e.g., amePLM [10], ICP4Life [11], Know4car [12], Manutelligence [13]). The importance of collaboration between design and manufacturing is highlighted in several papers [14, 15]. However, the practical use of tools for supporting knowledge management is still very low. The GeCo Observatory (http://www.homeappliancesworld .com/2015/06/01/italianmanufacturing-innovation-is-possible) found, on a sample of more than 100 Italian manufacturing companies, that the most used methods to explicit knowledge remain the traditional verbal or written communication, while the use of more structured software systems is severely limited.

Two lacks can be identified in both current scientific literature and research projects. The first one is that they did not address specifically the highly customized/prototypal production, where the presence of many alternative routings and operations makes very difficult to manage all the manufacturing variables together, in an efficient way, without increasing wastes of time and costs. The second 
one is that they did not address the problem of collecting data related to failures and anomalies occurring at the shop floor, and make them available for the designers, to allow them learning from past problems when designing new products and processes.

The main technical innovations proposed by our work are the following: (i) open source architecture for PLM, KBS and MES, (ii) advanced data model to relate data from PLM and MES, and (iii) possibility of storing data related to anomalies occurred during the production.

\section{Method}

Three systems are used to manage manufacturing information: PLM, MES and Enterprise Resource Planning (ERP). The integration of ERP and MES allows the organization an efficient management of the inventory. In fact, an ERP systems can more efficiently manage the purchase functions if it knows the consumption of raw materials in real time. The integration between ERP and MES is based on the IEC 62264 standard, a model that standardizes the exchange of information between business systems and production control systems. In order to guarantee a consistent flow of information in the company, the integration between PLM-ERP has also to be implemented. The most significant improvement is the integration of the organizational data, ensuring that all areas can access the updated product data.

These two integrations are not capable of guaranteeing the right flow of information between PLM and MES, because the ERP does not have an adequate structure to accept and store detailed data of the product. Therefore, the PLM-MES integration is necessary.

\subsection{Knowledge-based System}

The method we propose is to develop a central Knowledge based System (KBS), acting as integrator of the ERP, PLM and MES. The proposed system will allow (i) to collect all the information regarding the critical realizations of new components in a structured way, so that the added values of the experience breakthrough, as well as other useful tips, could be provided to the users, and (ii) to reuse the knowledge, i.e. help designers to define more reliable processes for new products, reducing the "trialand-error" cycles in the development of forming processes.

In fact, when a customer makes an order, it means that the company must define the sequence of activities to obtain the required product. If the historical data regarding previous products are stored in the KBS, it can be used to find the closest product already produced in the past that needs less changes to be adapted to the new shop order. The chosen product is then found in the PLM platform where the needed changes can be done. The information associated to the new product is sent to the KBS and made accessible to the MES. The MES uses the product information to manage the production and, when the production is finished, it reports in the KBS the information related to the execution of each activity and the success or failure of the 
product. In case of failure, the company can check the intermediate results reported for each activity and decide how to proceed to obtain a better solution.

\subsection{KBS Data Model}

The KBS contains the subset of data relevant for all the three systems and acting as a bridge among them. In the following, we focus in particular on the integration between PLM and MES. Fig. 1 shows the structure of the KBS through an entityrelationship model.

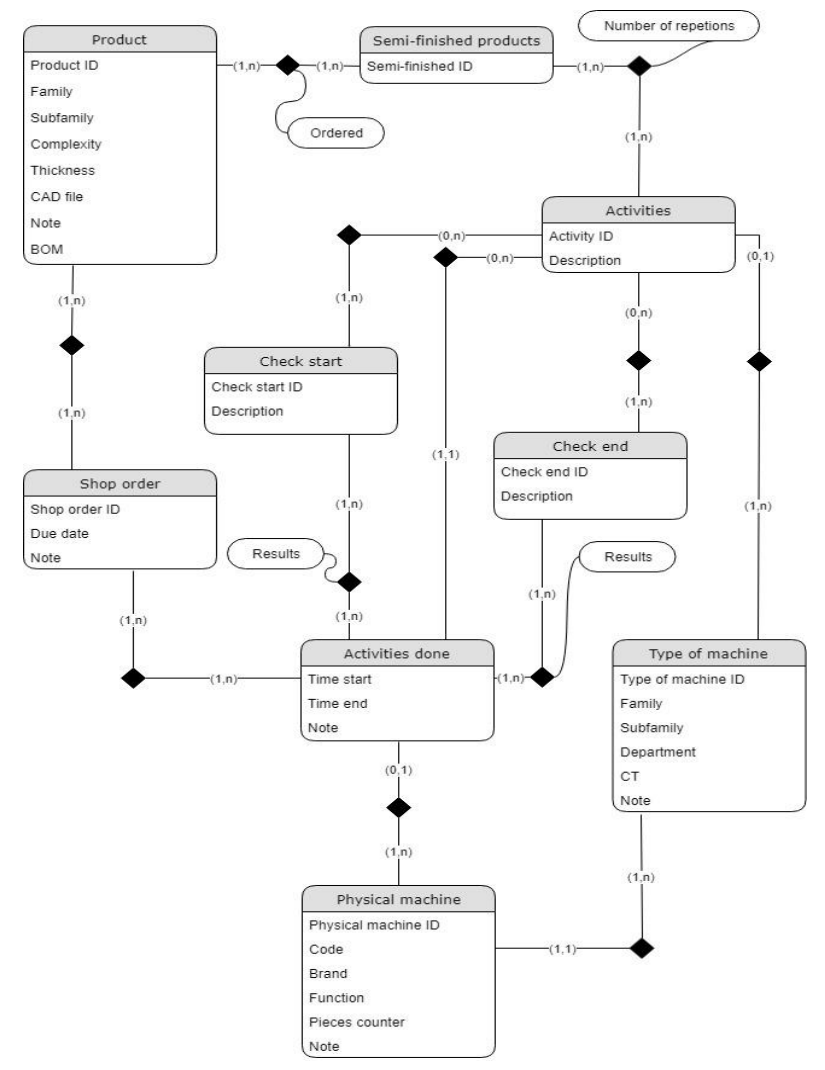

Fig. 1. UML class diagram of the data model of the KBS.

The product entity contains information about the classification, the CAD file, the BOM and other general characteristics of the products. The amount of the semifinished product is connected to it, which identifies the status of the semi-finished products specifying the next activity to be carried out. This is the reason why there is also the activity entity that characterizes the particular activity, explaining the check start, the check-ends and the machines necessary to carry it out. To each type of 
machine are then associated the physical machines available in the company. These entities are provided by the PLM and are subsequently used by the MES.

To the entities associated with the PLM activity are added entities that model the data provided by the MES, i.e. the data coming from the production. The fundamental entity is the one related to the shop order. In the KBS all the shop orders taken in charge and on which the company has worked are stored. This entity is connected to the product, as each shop order concerns a single and specific product, so a single and specific product lifecycle. The shop order is also connected to the activity carried out, connected itself to the verification checks. It models the data structure from which we can extract the history of all the activities divided by shop order and consequently by product and results obtained.

\subsection{KBS Implementation}

The KBS was implemented as a PostgreSQL database (www.postgresql.org), with the set of tables needed to represent the UML diagram of Fig. 1. The open source PLM software ARAS (www.aras.com) was exploited to digitalise and store the information related to the resources of the company and the production process of each product. Through an automatic procedure, the information related to the entities of Product, Semi-finished products, Activity, Check start, Check end, and Type of machine, together with their relationships, are periodically extracted from the PLM system and inserted in the KBS, to make them available to the MES and ERP systems.

The MES platform JPiano (https://www.aecsoluzioni.it/wp/en/jpianopanoramica/jpiano-prodotti) was used to implement the MES system. As for PLM, also from the MES the information related to the entities of Activities done and Physical machine, and their relationships and the ones with the Check start and Check end are periodically extracted and inserted in the KBS.

Further details on the implementation in a use case are reported in the following section.

\section{Use Case}

The framework was applied in an Italian company that operates in the automotive sector, producing prototype bodywork components for passenger cars and other kinds of vehicles. Currently, all the information generated during the production process is only written on paper.

The process for the realization of a prototype bodywork component starts with the delivery, by the costumer, of the CAD model of the requested piece. The CAD model is received by the technical office that defines the production process, the design of the dies and the material to be used. Once the dies have been constructed, the metal sheets used to make the body part are sent to the Laser office where the metal sheet is trimmed using a two-dimensional laser to obtain the appropriate shape outline. After the sheets have been cut, they are transported to the presses area where they undergo 
the first press operation. The semi-finished items are then returned to the laser section where 3D lasers cut the metal sheet according to specific laser paths obtaining the final measures of the piece and creating slots and holes.

We started the development of our framework with the implementation in ARAS of several graphic user interfaces in order to allow the users to store the data corresponding to the structure represented in Fig. 1. As an example, Fig. 2 presents the user interface to insert the information related the Type of machine entity. Similar interfaces were created for Activities, Product, Check start and Check end. For each activity, the corresponding machine, check starts and check ends can be added by selecting them from the drop down menus created.

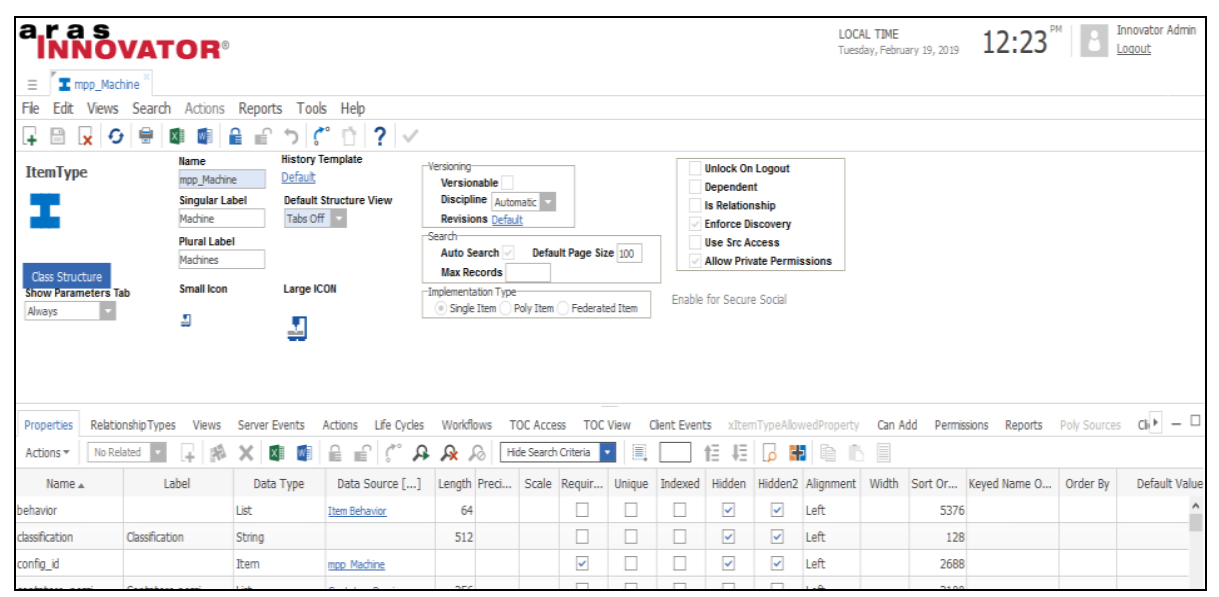

Fig. 2. Screenshot of Aras PLM implementation: Machine.

One of the main potentialities of our framework is the capability of inserting Check start and Check ends related to an activity. Examples of Check starts created for the use case are reported in Table 1. The Check starts represent the controls that the operators have to do before starting the execution of an activity on a machine. The list of Check starts for each Activity are set in the PLM and then transmitted to the KBS, so that they are accessible by the MES. In this way, the MES can show to the operators the Check starts when they start the execution of an activity. The results of the Check starts are inserted by the operators in the MES, which transmit them to the KBS, so they are accessible from the PLM.

Table 1. Examples of Check starts related to the Activities of the use case.

\begin{tabular}{ll}
\hline Activity & Check start \\
\hline 3D Laser welding & $\begin{array}{l}\text { Presence of a dedicated head } \\
\text { Presence of pincers for fixing the piece on the stand } \\
\text { Set of self-learning programming mode of welding path }\end{array}$ \\
Press punching & $\begin{array}{l}\text { Presence of the mold } \\
\text { Presence of mold mounting brackets }\end{array}$ \\
& $\begin{array}{l}\text { Presence of supports for handling sheet metal } \\
\text { Deep drawing }\end{array}$ \\
Presence of the mold
\end{tabular}




\begin{tabular}{ll} 
& Presence of mold mounting brackets \\
& Presence of supports for handling sheet metal \\
& Presence of nylon sheets \\
3D Laser finishing & $\begin{array}{l}\text { Presence of oil } \\
\text { Routes loaded with USB device } \\
\text { Presence of U-bolts for positioning the sheet } \\
\text { Presence of pincers for fixing the piece on the U-bolt }\end{array}$ \\
Manual molding & $\begin{array}{l}\text { Presence of reference holes } \\
\text { Presence of molds from the press department } \\
\text { Presence of gauges and hammers }\end{array}$ \\
\hline
\end{tabular}

Similarly, also for the Check ends, for each activity it is possible to specify which are the controls to do at the end of the operation. In the current version of the framework, the Check end is a free text where the operator can write if something went wrong during the operation. A more complex data collection, including the possibility of uploading a photo or a video of the anomalous results, is under development.

In ARAS, it is also possible to define a production process (i.e., the relationship between Activities and Product) by using the Process Plan module. In order to populate a process plan, a designer/planner can easily add the activities by selecting the activities from 'list of Activities' created before. The execution of each activity is then recorded by the MES, which insert the actual start and end date for each activity, so that a comparison between the planned dates and the actual ones can be performed.

To replicate data from ARAS to the KBS, a merge replication [15] was implemented. Merge replication starts with a snapshot of the source database objects and data. Subsequent data changes and schema modifications made at the source database and at the destination database are tracked with triggers. The source synchronizes with the destination when connected to the network and exchanges all rows that have changed since the last time synchronization occurred. In this way, the content of the PLM and the KBS are continuously updated and synchronized.

\section{Conclusions}

The objective of this paper is to propose a framework to integrate design and production data, since, especially in small manufacturing companies, they often remain separated and stored in two different systems: PLM and MES. The framework is based on a knowledge based system, which collects and integrates two subsets of data, one from PLM and one from MES, making such data accessible by both the systems. In this way, anomalies that occur at the shop floor during the production can be easily found by designers, who can use them to improve the process in order to improve the design of the following products. Furthermore, the proposed framework allows the data retrieval of previous products and its re-usage to define variants and changes to them.

Future works will consider on the one hand data analysis techniques for using the stored data in the KBS, and on the other hand a more comprehensive integration 
considering also the ERP system. Furthermore, a set of key performance indicators to evaluate the efficacy of the proposed framework in terms of reduction of time to finalize the process development will be studied.

\section{References}

1. Wortmann, J.C., Muntslag, D.R., Timmermans, P.J.M.: Customer-Driven Manufacturing. Chapman \& Hall, London, UK. (1997).

2. $\mathrm{Tu}, \mathrm{Y}$.: Production planning and control in a virtual one-of-a-kind production company. Computers in Industry, 34(3), 271-283, (1997).

3. Dean, P.R.; Tu, Y.L. \& Xue, D.: An Information System for One-of-a-Kind Production. International Journal of Production Research, Vol.47, No.4, pp. 1071-1087, (2009).

4. Bruno, G., Antonelli, D., Korf, R., Zimmermann, N.: Exploitation of a Semantic Platform to Store and Reuse PLM Knowledge. In:IFIP Advances in Information and Communication Technology, 438, pp. 59-66 (2014).

5. Bruno, G., Taurino, T., Villa, A.: An approach to support SMEs in manufacturing knowledge organization, Journal of Intelligent Manufacturing, 29(6), pp. 1379-1392, (2018).

6. Chungoora, N., Young, R., Gunendran, G., Palmer, C., Usman, Z., Anjum, N., CuttingDecelle, A., Harding, J., Case, K.: A model-driven ontology approach for manufacturing interoperability and knowledge sharing, Computers in Industry 64(4): 392-401, (2013).

7. David, M., \& Rowe, F.: What does PLMS (product lifecycle management systems) manage: Data or documents? Complementarity and contingency for SMEs, Computers in Industry (2015).

8. Efthymiou, K., Sipsas, K., Mourtzis, D., Chryssolouris, G.: On knowledge reuse for manufacturing systems design and planning: A semantic technology approach, CIRP Journal of Manufacturing Science and Technology, 8: 1-11, (2015).

9. Igba, J., Alemzadeh, K., Gibbons, P.M., \& Henningsen, K.: A framework for optimizing product performance through feedback and reuse of in-service experience. Robotics and Computer-Integrated Manufacturing, (2015).

10.Bruno, G., Korf, R., Lentes, J., Zimmermann, N.: Efficient management of product lifecycle information through a semantic platform, International Journal of Product Lifecycle Management, 9(1), pp.45-64, (2016).

11.Elgamma,A., Papazoglou, M., Krämer, B., Constantinescu, C.: Design for Customization: A New Paradigm for Product-Service System Development, Procedia CIRP, 64, pp.345-350, (2017).

12.Ebrahimi, A. H., Johansson, P.E.C., Bengtsson, K., Åkesson, K.: Managing Product and Production Variety - A Language Workbench Approach, Procedia CIRP, 17, pp. 338-344, (2014).

13.Petrucciani M., Marangi L., Agosta M., Stevanella M.: A Platform for Product-Service Design and Manufacturing Intelligence. In: Cattaneo L., Terzi S. (eds) Models, Methods and Tools for Product Service Design. SpringerBriefs in Applied Sciences and Technology. Springer, (2019).

14.Ming, X.G., Yan, J.Q., Lu, W.F. et al.: Mass production of tooling product families via modular feature-based design to manufacturing collaboration in PLM, J Intell Manuf, 18: 185 (2007)

15.Pouchard, L., Ivezic, N., Schlenoff, C.: Ontology engineering for distributed collaboration in manufacturing, Proceedings of the AIS2000 conference (2000)

16.Hammond B. Merge replication in Microsoft's SQL server 7.0, Proceedings of the 1999 ACM SIGMOD international conference on Management of data, 527 (1999). 